AUDIT

\title{
Central venous lines in neonates: a study of 2186 catheters
}

\section{W Cartwright}

See end of article for authors' affiliations

.....................

Correspondence to: Dr Cartwright, Royal Brisbane and Women's Hospital, RBH Post Office, Brisbane, Queensland 4029 Australia;

David_Cartwright@health. qld.gov.au

Accepted 19 April 2004

\begin{abstract}
Objective: To describe the use of percutaneously inserted silicone central venous lines (CVLs) in neonates at the Royal Brisbane and Women's Hospital, Australia.

Design: Data for all infants admitted from 1 January 1984 until 31 December 2002 who had a CVL were examined in the neonatal database, completed from paper records and patient charts where necessary. Autopsy reports of all babies who died with a catheter in place were reviewed.

Results: There were 18761 admissions, 2186 catheters in 1862 babies for a total of 35159 days (median 14 days, range 1-99 days). The tip was in the right atrium for $1282(58.6 \%)$ of the catheters. A total of 142 babies $(7.6 \%)$ died with a CVL in place, $89(4.8 \%)$ with the catheter tip in the right atrium. Thirty two of these 89 babies had an autopsy. No autopsies reported tension in the pericardium or milky fluid resembling intralipid. One case $10.05 \%$ of catheters) of non-lethal pericardial effusion occurred in a baby whose catheter was inappropriately left coiled in the right atrium. There were no cases of pleural effusion related to CVL use. Most (1523, 69.7\%) were removed electively. Septicaemia occurred during the life of 116 catheters (5.3\%).

Conclusion: This is the largest series of percutaneously inserted silicone central venous catheters reported. It illustrates the safety of these catheters in this context. It highlights the value of keeping prospective records on such catheters. Catheters with their tips in the right atrium and not coiled did not cause pericardial effusion. Strict insertion and management principles for CVLs should be adhered to.
\end{abstract}

addressed are the occurrence of pleural and pericardial effusions, septicaemia, and the reasons for line removal.

\section{METHODS}

The neonatal database was examined for all infants admitted from 1 January 1984 until 31 December 2002 who had a CVL. The database before 1 January 1996 recorded babies having a CVL, and total CVL days. From 1 January 1996, the dates of insertion and removal of each catheter, insertion site, tip position, removal reason, and organism grown from tip (all tips are cultured after removal) were also recorded. For all time periods, complications that were not a removal reason were recorded as miscellaneous diagnoses. These were examined for the occurrence of pericardial effusion and pleural effusion. Lines removed for suspected infection, later proven to be septicaemia, are reclassified as being removed for septicaemia. If the baby died, and was also septicaemic, reason for removal is classified as death+septicaemia.

Data before 1 January 1996 were completed from three sources:

(1) Original data abstraction sheets recording dates of insertion and removal were examined to retrieve these dates for individual catheters.

(2) From mid-1983 until mid-1991, an additional paper record of all CVLs had been kept (personal interest), containing dates of insertion and removal, tip position, reason for removal, and tip culture.

(3) For babies admitted between mid-1991 and 31 December 1995, data relating to tip position and reason for removal were completed by examination of about 500 charts. Fifteen could not be located.

Autopsy reports of all babies who died with a catheter in place were reviewed.

Abbreviations: CRBSI, catheter related blood stream infections; CVL,

central venous line
This paper describes the use of silicone central venous lines (CVLs) at Royal Brisbane and Women's Hospital. Specifically 
Table 1 Central venous lines inserted 1 January 1984 to 31 December 2002

\begin{tabular}{ll}
\hline Total & 2186 \\
$<750 \mathrm{~g}$ birth weight & 366 \\
$750-999 \mathrm{~g}$ birth weight & 593 \\
$1000-1499 \mathrm{~g}$ birth weight & 685 \\
$1500-1999 \mathrm{~g}$ birth weight & 152 \\
$\geqslant 2000 \mathrm{~g}$ birth weight & 390 \\
Birth weight (g) & $1056(340-5320)$ \\
Gestational age (weeks) & $28.3(22.6-42.3)$ \\
Duration of CVL (days) & $14(1-99)$ \\
\hline \multirow{2}{*}{ Values are number or median (range). }
\end{tabular}

\section{RESULTS}

Between 1 January 1984 and 31 December 2002, there were 18761 admissions to the neonatal unit, of whom 1862 had a CVL. There were 2186 catheters for a total of 35159 days (median 14 days per catheter). The longest life of any individual catheter was 99 days. Table 1 lists catheter use by birth weight groups for these babies, whose birth weights ranged between $340 \mathrm{~g}$ and $5320 \mathrm{~g}$, and whose birth gestational ages were between 22 weeks 6 days and 42 weeks 3 days. In the same time period, there were 19 surgically placed central venous catheters, and 11 percutaneously inserted non-silicone central venous catheters, which are not the subject of this report, except to say that none of these had pericardial or pleural effusion as a complication.

Records showed that $1282(58.6 \%)$ catheters had their tip position in the right atrium. A total of 142 babies $(7.6 \%$ of babies, $6.6 \%$ of catheters) died with a CVL in place, and the records show that in 89 (4.8\% of babies) of these the catheter tip was in the right atrium. Thirty two of the 89 babies who died with a line tip in the right atrium, and 20 of the remainder, had an autopsy. Nine autopsies in the right atrial group $(27 \%)$ reported some straw coloured fluid in the pericardial cavity, all in the context of generally oedematous babies. None reported tension in the pericardium or milky fluid consistent with parenteral nutrition having been infused there. Seven autopsies in the non-right atrial group $(35 \%)$ reported fluid in the pericardial cavity, none under tension and all straw coloured. Macroscopic and microscopic examination of the myocardium in each case did not reveal any localised abnormality, as would occur with a catheter complication.

One case $(0.05 \%$ of catheters) of pericardial effusion was identified in a baby whose catheter tip was recorded as being in the right atrium. At the time the catheter was actually curled in the right atrium, with its tip wedged in the right atrial-right ventricular junction, and had not been suffi-

Table 2 Reasons for central venous line removal (1 January 1984 to 31 December 2002)

\begin{tabular}{ll}
\hline No further need & $1523(69.7 \%)$ \\
Local oedema/infiltration & $153(7.0 \%)$ \\
Death & $119(5.4 \%)$ \\
Death+septicaemia & $23(1.1 \%)$ \\
Blocked/leaking/bleeding & $97(4.4 \%)$ \\
Septicaemia & $71(3.2 \%)$ \\
Suspected infection & $62(2.8 \%)$ \\
"Line accident" & $38(1.7 \%)$ \\
Unknown & $14(0.6 \%)$ \\
Inflamed insertion site & $13(0.6 \%)$ \\
Malpositioned tip & $10(0.5 \%)$ \\
Not recorded & $62(2.9 \%)$ \\
\hline
\end{tabular}

Unknown, Chart could not be found, and no other record; not recorded, all records found and viewed, but removal reason not clear from record.
Table 3 Organisms that caused septicaemia $(n=116)$

\begin{tabular}{l}
\hline CoNS \\
MRSA \\
Klebsiella sp \\
Pseudomonas sp \\
Enterococcus faecalis \\
Staphylococcus aureus \\
Escherichia coli \\
Candida sp \\
Enterobacter sp
\end{tabular}

CoNS, Coagulase negative Staphylococcus; MRSA, methicillin resistant

Staphylococcus aureus; GBS, Group B Streptococcus.

ciently pulled back after radiographic examination. It was pulled back when the baby had a pulmonary haemorrhage the night after catheter insertion. Pericardial effusion was found on echocardiographic examination two days later.

There were no cases of pleural effusion related to CVL use.

Table 2 lists reasons for catheter removal. Most (1523, $69.7 \%$ ) were removed electively (no longer needed). The greatest chance of elective removal was for catheters with the tip recorded as being in the right atrium (77.8\% of 1282), with the next being for catheters with the tip recorded as being in the superior vena cava $(76.6 \%$ of 239$)$. There was a $50 \%$ chance or less of elective removal of catheters with the tip in the subclavian vein or a limb vein.

Of the 142 babies whose catheters were removed because the baby died, 23 were septicaemic at the time. A further 71 catheters were removed after the diagnosis of septicaemia or because of suspected infection later proven to be septicaemia-that is, 94 catheters $(4.25 \%)$ were removed for septicaemia with or without death. It is unit practice to remove catheters after a diagnosis of septicaemia. This practice, however, has not been strictly adhered to over the past five years, resulting in 22 cases of septicaemia being treated with the catheter remaining in. There were therefore 116 catheters where septicaemia occurred during the life of the catheter $(5.3 \%)$. From 1 January 1996 to 31 December 2002, the dates of all septicaemic episodes were recorded, allowing analysis of catheter related blood stream infection (CRBSI) as the number of instances of septicaemia occurring at least 48 hours after placement of a catheter or within 48 hours after removal of the catheter. In this time period, there were 72 instances of CRBSI (3.82/1000 line days). The highest risk group for CRBSI was babies of $<750 \mathrm{~g}$ birth weight (30 instances, $8.2 \%$ of catheters, $8.62 / 1000$ line days), followed by those of 750-999 g birth weight (19, 3.2\%, 3.53/ 1000 line days). The lowest incidence of CRBSI was in babies of 1000-1499 $\mathrm{g}$ birth weight (10, 1.5\%, 1.7/1000 line days), and a slightly higher incidence was seen in babies of $\geqslant 1500 \mathrm{~g}$ birth weight (13, 2.4\%, 3.07/1000 line days).

Table 4 Insertion and management principles

1. Inserted by experienced staff (consultant or senior registrar) 2. Aim to insert too far and pull back away from vessel walls

3. Never leave a catheter where it does not easily and repeatedly withdraw blood during the insertion procedure

4. ALWAYS inject with radio-opaque contrast for $x$ ray examination (if you don't inject it, you don't know where the tip is)

5 . Be actively injecting during $x$ ray examination to see contrast coming from the end of the catheter

6. Sterile technique for insertion, and for line changes (three times/week)

7. No drug injections - catheter used for parenteral nutrition only

8. Antifungal prophylaxis of oral and topical nystatin

9. Cover insertion site with bio-occlusive dressing and leave undisturbed. No coils of catheter under dressing 
Coagulase negative staphylococci ( $24.3 \%$ of organisms) predominated among organisms causing septicaemia (table 3). Methicillin resistant Staphylococcus aureus (MRSA) was prominent in the period 1987-1991 when colonisation with MRSA was endemic in our nursery, but after its elimination in 1991, ${ }^{29}$ MRSA septicaemia has occurred only twice (1995 and 2001). There were only five cases of Candida septicaemia while a CVL was in place. Two of these were in babies of $<1000 \mathrm{~g}$ birth weight. No fungomas were seen. Prophylaxis with oral and topical nystatin was introduced in 1980 after a number of cases of Candida septicaemia in 19791980, most associated with peripheral parenteral nutrition delivery.

There was only one case of endocarditis ( $S$ aureus).

Apart from the case of pericardial effusion noted above, there was one other life threatening complication in the occurrence of neck oedema with respiratory obstruction a few hours after catheter insertion, requiring endotracheal intubation and catheter removal. The catheter tip had extravasated into the neck.

\section{DISCUSSION}

This is the largest series of percutaneously inserted silicone central venous catheters reported. It highlights that in the Royal Brisbane and Women's Hospital, where catheters are electively positioned with their tip in the right atrium, these catheters are very safe, and are associated with low complication rates. It also highlights the value of keeping prospective data on such catheters. If we do not do this, it may well be imposed on us. ${ }^{28}$

The two most important complications of these catheters are septicaemia and pericardial or pleural effusions. The 5.3\% incidence of septicaemia reported here is in the lower range of reported rates, which vary from 0 to $46 \% .^{30-39}$ Only two of the five cases of septicaemia caused by Candida sp in this series occurred in 959 catheters $(0.2 \%)$ in babies of $<1000 \mathrm{~g}$ birth weight. This compares favourably with a report ${ }^{40}$ describing the use of fluconazole to reduce fungal colonisation and septicaemia in extremely low birthweight babies with central venous catheters. Fungal (Candida) colonisation was reduced from $60 \%$ to $22 \%$, and invasive Candida infection from $20 \%$ to $0 \%$ in 50 patients. Candida septicaemia has been very uncommon since the introduction of fungal prophylaxis, which has not been subjected to controlled trial. A trial of oral nystatin alone in 67 infants of $<1250 \mathrm{~g}$ birth weight showed it to be effective in reducing infection and mortality. ${ }^{41}$ CRBSI is an unavoidable risk given that babies in whom a CVL is used are immunocompromised by virtue of extreme prematurity or at high risk of infection because of gastrointestinal complications. When septicaemia occurs, it is often clear that the catheter was not the source of infection, but it is proper to include all in the CRBSI rate calculation as "catheter related". It is likely that the reason behind the higher incidence of CRBSI in larger babies is that such babies

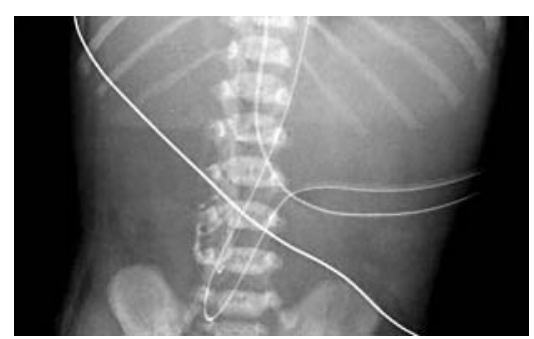

Figure 1 Distinctive pattern of dye in paravertebral veins. Central venous line with tip curled in the right ascending lumbar vein. Reprinted with permission from Cartwright D, J Paediatr Child Health 2004;40:332-3.

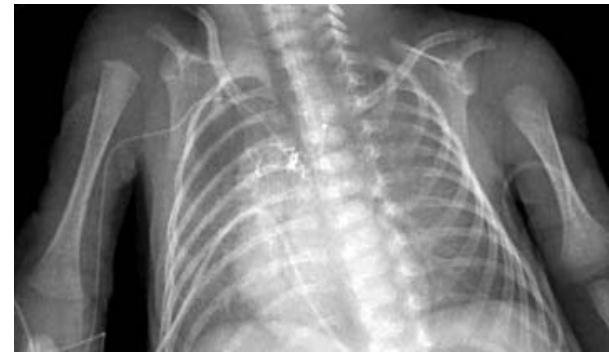

Figure 2 Central venous line tip in the small vein near the superior vena cava-this may be in the vasa vasorum of the superior vena cava. It would not be a good place to infuse parenteral nutrition solutions. If not injected, this line would appear to be in a satisfactory position.

have different indications for CVL insertion-more likely to have serious abdominal pathology or surgery. The data on CRBSI by birth weight groups compare favourably with data from the National Nosocomial Infections Surveillance systems. ${ }^{42}$

Significant recently has been the question of pericardial effusion and consequent cardiac tamponade, reported in 1$3 \%{ }^{10}$ of babies with a CVL, with a $30-50 \%$ mortality. It is most commonly reported with catheter tips thought to be in the right atrium. In some, a catheter tip thought to have been in the right atrium has been shown to have been elsewhere, such as the right ventricle, ${ }^{11}$ or looped in and caught up against the wall of the right atrium. ${ }^{36}$ Some authors describe migration of catheter tips ${ }^{414}$ from initial positions outside the cardiac chambers, with two of those reports ${ }^{4}$ not describing catheter fixation methods. The third ${ }^{14}$ describes a fixation method that seems inherently likely to allow catheter migration. These instances highlight the difficulty sometimes experienced in locating catheter tips, particularly when "radio-opaque" catheters are inserted and plain radiography alone is used for tip localisation. ${ }^{43}$ In fact, I believe this complication has only ever been reported with the use of "radio-opaque" catheters; perhaps the need to contrast inject radiolucent catheters is protective against it. No cases of cardiac tamponade were identified associated with the 1281 catheters with their tips located appropriately in our intended right atrial location. One catheter inappropriately left looped in the right atrium with its tip wedged at the edge of the tricuspid valve was associated with pulmonary haemorrhage and bradycardia eight hours after insertion as described above.

In response to reports of death from cardiac tamponade, some catheters now bear a manufacturer's recommendation that they not be placed with the tip in the right atrium. The UK Department of Health has made similar recommendation, ${ }^{28}$ and the US Food and Drug Administration implicitly so by posting a paper recommending placement of CVL tips outside the heart on their website. ${ }^{44}$ This complication has, however, been described for catheters with tips located outside the heart. ${ }^{12}$ Why has it not been seen in this series? The most obvious possible explanation is that it has in fact occurred, but has not been identified. Every effort has been made to ensure that this is not the case. In addition, the occurrence of cardiac tamponade is dramatic, not to escape notice, to be both recorded and remembered. Complications of managements are rigorously recorded at the time they occur, and the database search methods used would reveal these.

Our preferred catheter has been the "original" epicutaneo cave catheter (2184.06; Vygon, Uppsala, Sweden), which is not visible on plain radiograph, and so requires radio-opaque contrast injection for localisation (that catheter is no longer available, as ISO standard 10555-3 now requires all such 


\section{What is already known}

- Percutaneously inserted central venous catheters are regarded as life saving in providing nutrition to small neonates

- Pericardial effusion and cardiac tamponade have been reported in 1-3\% of neonates having such a catheter, with death in $30-50 \%$ of cases

- Septicaemia has been reported in up to $46 \%$ of neonates having such a catheter

catheters to be radio-opaque). The insertion site is dressed with a "bio-occlusive dressing" (Johnson \& Johnson, Piscataway, New Jersey, USA), not disturbed during the life of the catheter unless soiled or at risk of coming off (very rare). No steri-strips are used. The catheter is brought straight out from under the dressing, avoiding the possibility of inward migration. Strict insertion and management principles for CVLs (table 4) may add to their safety. Most important to us are restricting operators to experienced personnel, and ensuring that blood can be readily and repeatedly withdrawn from the catheter where it will be left at the completion of insertion, to ensure it is in a large vessel and is not lodged against a vessel or cardiac chamber wall. Instructions packaged with one catheter (epicutaneo cave radio-opaque 2184.00; Vygon) state that blood should not be withdrawn during the insertion. I strongly disagree with this recommendation. Crucial also is the practice of contrast injection for tip localisation. Even when radio-opaque catheters are used, we always inject the catheter for tip localisation, as described by Shaw, ${ }^{1}$ and reaffirmed by Reece et al ${ }^{43}$ Chandran and Chong, ${ }^{45}$ and Makwana et al. ${ }^{46}$ Injection continues during radiographic exposure, leaving a blush of contrast visible at the catheter tip. There is then no doubt as to the location of the catheter tip. A catheter caught in interstices within the heart, such as against the right atrial wall, is very visible, as are unusual positions such as the ascending lumbar vein (fig 1) or small vessels near the superior vena cava (fig 2). This could be thought to be satisfactorily positioned in the superior vena cava if a radioopaque catheter were used with plain radiography only. Contrast injection can also alert to abdominal wall vein positioning (fig 3), recently reported to have caused hypoglycaemia and an incorrect diagnosis of necrotising enterocolitis. ${ }^{20}$ Catheters in the ascending lumbar vein have been associated with serious morbidity and mortality, ${ }^{24-26}$ but are easily identified by contrast injection. Since August 2000, we have used digital computed radiography which has also been reported to enhance tip localisation. ${ }^{47}$

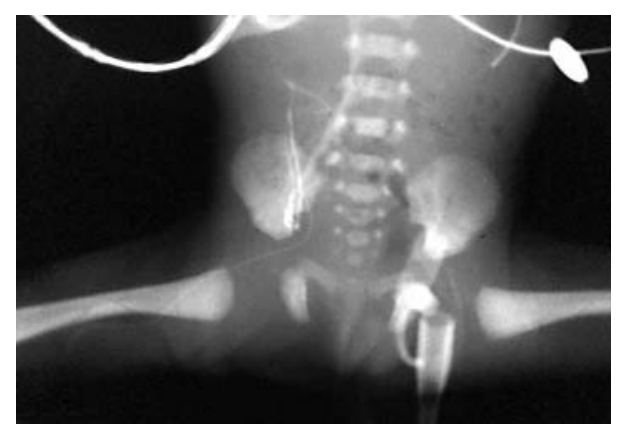

Figure 3 Central venous line tip in an anterior abdominal wall vein, easily determined when the catheter is injected with radio-opaque dye.

\section{What this study adds}

- Only one case of pericardial effusion, non-lethal, was seen in 2186 catheters, and that in a catheter shown to be incorrectly positioned and not properly adjusted

- No cases of catheter associated pleural effusion were seen

- Septicaemia occurred associated with $5.3 \%$ of catheters. Infection risks are greatest with the smallest babies

- The use of percutaneously inserted central venous catheters is safe, in a unit where strict management guidelines are followed, including the demonstration of catheter tip position by contrast radiography

In this unit, CVLs are not routinely used for drug injections. All line changes, routinely three times a week, are done with full surgical scrub by the operator, with a mask being worn by the assistant. If an infusion is to be added, the same rigorous principles are followed in setting it up. Very occasionally a CVL will be used for antibiotic treatment. The same infusion set up procedures are used, and a number of doses of antibiotic are set up on the line to be infused when required by turning a three way tap, minimising line breaks.

This analysis of our CVL dataset endorses the safety of placing catheter tips in the right atrium with contrast injection localisation, and illustrates the value of keeping records of all intravascular catheters as suggested in the Manchester Report. $^{28}$

\section{ACKNOWLEDGEMENTS}

I acknowledge the assistance of Dr Mark Davies in reviewing the manuscript, and of medical student Ms Penny Reimers who assisted in chart review.

\section{REFERENCES}

1 Shaw JCL. Parenteral nutrition in the management of sick low birthweight infants. Pediatr Clin North Am 1973;20:333-58.

2 Fioravanti J, Buzzard CJ, Harris JP. Pericardial effusion and tamponade as a result of percutaneous silastic catheter use. Neonatal Netw 1998;17:39-42.

3 Beattie PG, Kuschel CA, Harding JE. Pericardial effusion complicating a percutaneous central venous line in a neonate. Acta Paediatr 1993;82:105-7.

4 Nadroo AM, Lin J, Green RS, et al. Death as a complication of peripherally inserted central catheters in neonates. J Pediatr 2001;138:599-601.

5 Keeney SE, Richardson CJ. Extravascular extravasation of fluid as a complication of central venous lines in the neonate. J Perinatol 1995; 15:284-8.

6 Aiken G, Porteous L, Tracy M, et al. Cardiac tamponade from a fine silastic central venous catheter in a premature infant. J Paediatr Child Health 1992;28:325-7.

7 Rogers BB, Berns SD, Maynard EC, et al. Pericardial tamponade secondary to central venous catheterization and hyperalimentation in a very low birthweight infant. Pediatr Pathol 1990;10:819-23.

8 Garg M, Chang CC, Merritt RJ. An unusual case presentation: pericardial tamponade complicating central venous catheter. J Perinatol 1989;9:456-7.

9 Nowlen T, Rosenthal GL, Johnson GL, et al. Pericardial effusion and tamponade in infants with central catheters. Pediatrics 2002;110:137-42.

10 Beardsall K, White DK, Pinto EM, et al. Pericardial effusion and cardiac tamponade as complications of neonatal long lines: are they really a problem? Arch Dis Child Fetal Neonatal Ed 2003;88:F292-5.

11 Leipala JA, Petaja J, Fellman V. Perforation complications of percutaneous central venous catheters in very low birthweight infants. J Paediatr Child Health 2001;37:168-71.

12 Wirrell EC, Pelausa EO, Allen AC, et al. Massive pericardial effusion as a cause for sudden deterioration of a very low birthweight infant. Am J Perinatol 1993:10:419-23.

13 Sasidharan P, Billman D, Heimler R, et al. Cardiac arrest in an extremely low birth weight infant: complication of percutaneous central venous catheter hyperalimentation. J Perinatol 1996;16:123-6.

14 Madhavi P, Jameson R, Robinson MJ. Unilateral pleural effusion complicating central venous catheterisation. Arch Dis Child Fetal Neonatal Ed 2000;82:F248-9.

15 Seguin JH. Right-sided hydrothorax and central venous catheters in extremely low birthweight infants. Am J Perinatol 1992;9:154-8. 
16 Nour S, Puntis JW, Stringer MD. Intra-abdominal extravasation complicating parenteral nutrition in infants. Arch Dis Child Fetal Neonatal Ed 1995;72:F207-8.

17 Lawrenz-Wolf B, Herrmann B. Pericardial tamponade caused by catheter infection in an extremely small premature infant. Monatsschr Kinderheilkd 1993;141:932-5.

18 Cupitt JM. An unusual complication of a central venous catheter in a neonate Paediatr Anaesth 2000;10:665-8.

19 Cheah FC, Boo NY, Latif JY. An unusual case of refractory hypoglycaemia in a neonate receiving total parenteral nutrition. Acta Paediatr 2000;89:497-8.

20 Baker J, Imong S. A rare complication of neonatal central venous access. Arch Dis Child Fetal Neonatal Ed 2002;86:F61

21 Williams JH, Hunter JE, Kanto WP Jr, et al. Hemidiaphragmatic paralysis as a complication of central venous catheterization in a neonate. J Perinatol 1995; 15:386-8.

22 Pleasure JR, Shashikumar VL. Phrenic nerve damage in the tiny infant during vein cannulation for parenteral nutrition. Am J Perinatol 1990;7:136-8.

23 Zenker M, Rupprecht T, Hofbeck M, et al. Paravertebral and intraspinal malposition of transfemoral central venous catheters in newborns. J Pediatr 2000;136:837-40.

24 Chen CC, Tsao PN, Yau KI. Paraplegia: complication of percutaneous central venous line malposition. Pediatr Neurol 2001;24:65-8.

25 Rajan V, Waffarn F. Focal neurological manifestations following aberrant central venous catheter placement. J Perinatol 1999;19:447-9.

26 Bass WT, Lewis DW. Neonatal segmental myoclonus associated with hyperglycorrhachia. Pediatr Neurol 1995;13:77-9.

27 Hurst RW, Kerns SR, Mcllhenny J, et al. Neonatal dural venous sinus thrombosis associated with central venous catheterization: $C T$ and MR studies. J Comput Assist Tomogr 1989;13:504-7.

28 Department of Health (UK). Review of the deaths of four babies due to cardiac tamponade associated with the presence of central venous catheter. www.doh.gov.uk/manchesterreport/manchesterreport.pdf, 2001

29 Webster J, Faoagali JL, Cartwright D. Elimination of methicillin-resistant Staphylococcus aureus from a neonatal intensive care unit after hand washing with triclosan. J Paediatr Child Health 1994;30:59-64.

30 Ainsworth SB, Furness J, Fenton AC. Randomized comparative trial between percutaneous longlines and peripheral cannulae in the delivery of neonatal parenteral nutrition. Acta Paediatr 2001;90:1016-20.

31 Trotter CW. Percutaneous central venous catheters in neonates: a descriptive analysis and evaluation of predictors for sepsis. J Perinatal Neonatal Nurs $1996 ; 10: 56-71$.
32 Trotter CW. Percutaneous central venous catheter-related sepsis in the neonate: an analysis of the literature from 1990 to 1994. Neonatal Netw 1996; 15:15-28.

33 Maas A, Flament $P$, Pardou $A$, et al. Central venous catheter-related bacteraemia in critically ill neonates: risk factors and impact of a prevention programme. J Hosp Infect 1998;40:21 1-24.

34 Fallat ME, Gallinaro RN, Stover BH, et al. Central venous catheter bloodstream infections in the neonatal intensive care unit. J Pediatr Surg 1998;33:1383-7.

35 Yeung $\mathrm{CY}$, Lee $\mathrm{HC}$, Huang $\mathrm{FY}$, et al. Sepsis during total parenteral nutrition: exploration of risk factors and determination of the effectiveness of peripherally inserted central venous catheters. Pediatr Infect Dis 1998;17:135-42.

36 Parellada JA, Moise AA, Hegemier S, et al. Percutaneous central catheters and peripheral intravenous catheters have similar infection rates in very low birth weight infants. J Perinatol 1999; 19:251-4

37 Neubauer AP. Percutaneous central i.v. access in the neonate: experience with 535 silastic catheters, Acta Paediatr 1995;84:756-60.

38 Soong WJ, Hwang B. Percutaneous central venous catheterization: five year experiment in a neonatal intensive care unit. Acta Paediatrica Sinica 1993;34:356-66.

39 Battin M, Page B, Knight D. Percutaneous intravenous central catheters. J Paediatr Child Health 2001;37:527.

40 Kaufman D, Boyle R, Hazen KC, et al. Fluconazole prophylaxis against fungal colonization and infection in preterm infants. N Eng J Med 2001;345: 1660-6

41 Sims ME, Yoo Y, Salminen C, et al. Prophylactic oral nystatin and fungal infections in very-low-birthweight infants. Am J Perinatol 1988:5:33-6.

42 NNIS System. National Nosocomial Infections Surveillance (NNIS) System report. Am J Infect Control 2003;31:481-98.

43 Reece A, Ubhi T, Craig AR, et al. Positioning long lines: contrast versus plain radiography. Arch Dis Child Fetal Neonatal Ed 2001;84:F129-30.

44 Yoder D. Cardiac perforation and tamponade:the deadly duo of central venous catheters. Int J Trauma Nurs. 2001;7: 108-12, FDA website: www.accessdata.fda.gov/scripts/cdrh/cfdocs/psn/transcript.cfm?show $=1$.

45 Chandran S, Chong E. Delayed presentation of a neonatal long line incident. $J$ Paediatr Child Health 2003:39:719.

46 Makwana N, Lander A, Buick R, et al. Unusual complication of a central venous line in a neonate. Arch Dis Child Fetal Neonatal Ed 2003;88:F440.

47 Evans A, Natarajan J, Davies CJ. Long line positioning in neonates: does computed radiography improve visibility? Arch Dis Child Fetal Neonatal Ed 2004;89:F44-5. 